\title{
Utilizing a Simple Numerical Model in Discrete Element Analysis to Simulate Flow Time and Number Tests of Asphalt Mixes
}

\author{
A.M.A. Abdo \\ Department of Civil and Environmental Engineering, Dhofar University, PO Box 2509, Salalah - 211, \\ Sultanate of Oman
}

Received 4 July 2013; accepted 22 May 2014

\begin{abstract}
During the past decades, many numerical models have been used to predict responses of asphalt mixes under different types of loading. Some of these models were simple due to practicality but overestimated the response of asphalt mixes. On the other hand, sophisticated but effective numerical models have been developed to address the shortcomings of the simpler models, and were used mostly in finite element analysis (FEA). However, these models were complicated and not user friendly. Recently, the approach of the discrete element method (DEM) was adopted. Unlike traditional FEA, DEM can simulate crack propagation by allowing the separation of elements in the simulated models. Understanding these challenges, this study was initiated to investigate the utilization of a simple visco-elasto-plastic model that had been used successfully in predicting deformation in asphalt mixes using the DEM embedded in Particle Flow Code in Two Dimensions (PFC2D) software simulations. Simulation results, when compared to flow time $\left(\mathrm{F}_{\mathrm{T}}\right)$ and number $\left(\mathrm{F}_{\mathrm{N}}\right)$ test results, showed that this model could simulate actual tests, thus predicting deformation of asphalt mixes using the DEM on a larger scale.
\end{abstract}

Keywords: Asphalt mixes, Numerical modeling, Discrete element method, Flow time test, Flow number test, Deformation.

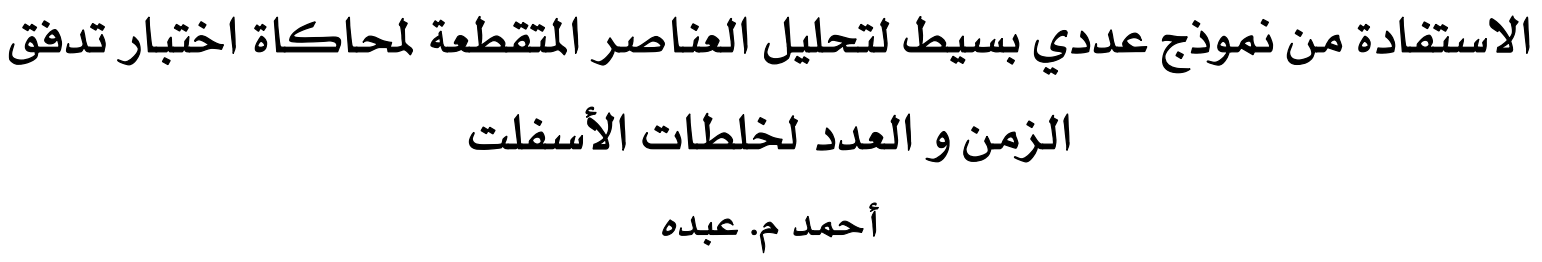

الملخص: خلال العقود الماضية تم استخدام نماذج عددية كثيرة للتبؤ برد الفعل لخليط الأسفلت لأحمال مختلفة. بعض هذه النهاذج كان بسيطاً نتيجة للتطبيق العملي و لكن كانت مبالغة ِِّ تقدير رد الفعل لخليط الأسفلت. على الجانب

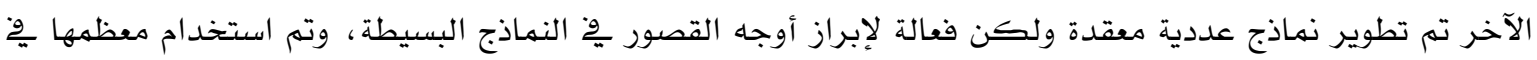
تحليل العناصر المحددة. لكن هذه الطرق معقدة وليست ودية للمستخدم. اعتمد حديثاً نهج طريقة العنصر المتقطع. هذه الطريقة بخلاف طريقة العناصر المحددة يمكنها محاكاة انتشار التصدع عن الطريق السهاح بفصل العناصر ِِّ نهوذج المحاكاة. بعد فهم هذه التحديات، هذه الدراسة هدفت الى فحص استخدام نموذج فيسكو البلاستيكي المرن بنجاح ِو. توقع التشوه وِ خلطات الأسفلت باستخدام طريقة العنصر المتقطع المرتبط بيرنامج PFC للهحاكاة. نتائج المحاكاة قورنت بنتائج تدفق الزمن و العدد وأظهرت أن هذا الاختبار يستطيع محاكاة الاختبارات الحقيقية و بالتالي يهكن التتبؤ بالتشوه وِخ خلطات الأسفلت باستخدام طريقة العنصر المتقطع على نطاق واسع.

مفاتيح الكلمات: خلطات الأسفلت ، التمثيل العددي ، طريقة العنصر المتقطع ، اختبار تدفق الزمن، اختبار تدفق العدد *Corresponding author's e-mail: aabuabdo@du.edu.om و التشوه 


\section{Introduction}

Flexible asphalt pavements are being subjected to more diverse and harsher loading conditions than ever before. However, even after adjusting design factors to account for these conditions, the adopted design techniques, which were developed using simple models, fall short of predicting failures as efficiently as they were able to do in the past. Additionally, it is difficult to take all properties into consideration while designing flexible pavement. Asphalt mix is a viscoplastic and anisotropic material. It varies in terms of its temperature, loading time, and aggregate orientation dependency. Thus, designers have chosen to overlook those properties in favor of simplifying the design process.

Plastic deformation, known as rutting, is the major distress pavement designers encounter. In order to prevent this type of premature failure and any undesired effects due to permanent deformations, as well as to account for the complex material properties of asphalt mixes, a more realistic model is essential. Incorporating the development and adoption of such material models into design methodologies will result in an improvement of performance and a reduction in maintenance.

Recent studies simulated asphalt mixes' responses to different types of loading conditions. By utilizing numerical models to describe a mesh of elements that simulated test setups, numerical solutions based on finite element analysis (FEA) were found. A study by Buttlar et al. (2003) suggested that most existing analysis models did not directly account for the continuous grading of properties in flexible pavements. They presented the application of a numerical model embedded in FEA software for asphalt pavement analysis. Masad et al. (2005) used an anisotropic non-associated flow rule based on the Drucker-Prager yield criterion. The model parameters were related to the experimental measurements of aggregates' characteristics and microstructure damage, which was measured using $\mathrm{X}$-ray tomography and image analysis techniques.

Tashman et al. (2005) introduced a microstructure-based viscoplastic continuum model for predicting permanent deformation of asphalt mixes. This model took into consideration strain rate and confining pressure dependency, dilation, aggregate friction, anisotropy, and damage, all of which have a huge impact on the permanent deformation of asphalt mixes at high temperatures. The developed model predictions were in good agreement with the experimental measurements. A disadvantage of FEA is that it will not allow the separation of elements during analysis. Thus, no formation of micro or macro cracks in the modeling of asphalt mixes under loading will occur.

\section{The Discrete Element Method (DEM)}

Recently, more attention has been directed to the DEM, which was introduced in 1971 to analyze problems with rock mechanics, ice formation and flow in streams, as well as earthquakes, impacts, and explosion damage to structures. The discrete element algorithm models a continuum as a system of distinct, interacting, and general-shaped particles subjected to laws of motion and deformation, which are bonded together. When the maximum stress in a contact bond is reached, the bond is broken and a separation of these particles, evidenced as cracks, can be observed (Cundall and Strack 1979). In the DEM, the complex constitutive behavior of a material is simulated by associating simple constitutive models with each particle contact. Shear and normal stiffness, static and sliding friction, and inter particle cohesion are three of the simpler contact models that can be employed (You 2003).

You and Buttlar (2006) argued that the DEM is a fundamental way of looking at the complex behavior and heterogeneity of asphalt mixes. They suggested that the DEM could be used to simulate asphalt mixes responses under different loading and temperature conditions. They represented the DEM approach as a research tool for modeling asphalt mix microstructure.

Abbas et al. (2007) utilized the DEM to develop a micromechanical model that accounted for viscoelastic behavior of asphalt mixes. Asphalt mix microstructure was captured using gray scale images of vertically 
cut sections of the compacted samples. Collop et al. (2006) investigated the use of the DEM by utilizing the Burger model to describe the contact bonds in their analysis under compression. They argued that the behavior of the mixture would be dominated by asphalt binder and complex aggregates interlock effects could be minimized. It was found that tested mixes dilated when the ratio of compressive to tensile contact stiffness increases as a function of loading time.

Recent studies (Yang et al. 2012; Liu et al. 2012; Cai et al. 2013) suggested that the DEM, via Particle Flow Code in Two Dimensions $\left(\mathrm{PFC}^{2 \mathrm{D}}\right)$ and Particle Flow Code in Three Dimensions (PFC ${ }^{3 \mathrm{D}}$ ) software (Itasca International Inc., Minneapolis, Minnesota, USA), could be used to predict the rutting resistance of asphalt mixtures more conveniently, by simulating the different test setups of asphalt mixes. The simulation results showed that the discrete element simulation and laboratory test had good correlation, which verified the applicability of these adopted models.

When it was developed, the main function of the DEM was to act as a tool to perform research to help with understanding the behavior of granular materials. However, it has been used recently in biomechanics, petrochemical engineering, fluid mechanics, and different structural engineering applications in which particle models were used to simulate material behavior in real engineering problems that involve complicated deformation patterns (Shibata et al. 2003; Goda and Ebert 2005; Mas Ivars 2006; Mahmoud et al. 2010; Jinag et al. 2010; Lau et al. 2011; Krabbenhoft et al. 2012; Abu Abdo et al. 2012; Abraham et al. 2013; Nakamura et al. 2013).

\section{Scope}

The main purpose of this study was to supplement previous research conducted in the area of hot mixture asphalt (HMA) evaluation. This study investigated the utilization of a simple visco-elasto-plastic model that had been used successfully in predicting deformation in asphalt mixes (Abu Abdo 2012). The goal of simulating laboratory tests in DEM was to verify the ability of this simplified predictive model to determine the simplified predictive model and the deformation of asphalt mixes on a larger scale under different loading conditions.

\section{Particle Flow Code in Two Dimensions (PFC ${ }^{2 D}$ ) Software}

$\mathrm{PFC}^{2 \mathrm{D}}$ is a platform for conducting the complicated calculations of the DEM, where representative elements containing several hundred particles are tested numerically. Continuum methods are used to solve real problems that involve complicated deformation patterns (Itasca 2006).

In $\mathrm{PFC}^{2 \mathrm{D}}$, particles' interactions are treated as a dynamic process with states of equilibrium developing whenever the internal forces balance. Each particle is assigned contact bonds to all adjacent particles and will break when ultimate strength is reached. Contact forces and displacements of a loaded body of particles are found by mapping the movements of the individual particles, which is dependable on the physical properties of the discrete system. The calculations performed in $\mathrm{PFC}^{2 \mathrm{D}}$ alternate between the application of Newton's second law of particles and a forcedisplacement law of contacts. Newton's second law is used to determine the motion of each particle arising from the contact and body forces acting on it, while the forcedisplacement law is used to update the contact forces arising from the relative motion at each contact (Itasca 2006).

Most numerical modeling of asphalt mixes under axial compressive loading uses the Burger model to describe contact bonds between particles in $\mathrm{PFC}^{2 \mathrm{D}}$ simulations (Schwarz and Weeks 1977; Ye et al. 2009; Zelelew and Papagiannakis 2009). In this study, the sea ice model (Schwarz and Weeks 1977; Mellor 1981 and Abu Abdo 2012) was used for its better representation of the contact bonds between particles. Commonly, sea ice, which is similar to asphalt mixes, exhibits time-dependency, mainly delayed elastic recovery and creeping. Many experiments have shown that ice strength has a dynamic value depending non-linearly upon the strain rate. The strain-stress relation that describes the sea ice behavior under loading is described in Eqn. (1). 
$e_{T}=\frac{\sigma}{E}+c\left(\frac{d_{o}}{d}\right)\left(\frac{\sigma}{E}\right)^{S} \cdot\left[1-e^{-\left(a_{T} \cdot t\right)^{b}}\right]+$

$e_{v o}^{\cdot} \cdot t \cdot\left(\frac{\sigma}{\sigma_{o}}\right)^{n}$

where,

$\sigma$ is the applied stress $(\mathrm{kPa})$,

$E$ is the mix stiffness ( $\mathrm{kPa})$,

$c$ is a material constant,

$b$ is a time exponent for delayed elastic strain,

$a_{T}$ is a material constant $\left(\mathrm{s}^{-1}\right)$,

$d$ is an average grain diameter ( $\mathrm{mm})$,

$d_{o}$ is a grain diameter $(\mathrm{mm})$,

$s$ is the stress exponent for grain-bound sliding,

$n$ is the degree of viscosity power law, and

$e_{v o}$ is the viscous strain rate $\left(\mathrm{s}^{-1}\right)$.

A study by Abu Abdo (2012) suggested that the sea ice model could be used effectively in predicting deformation in asphalt mixes under static and cyclic loading conditions. The model parameters were easily determined, and could be adapted to many numerical methods and used effectively in predicting the deformation of asphalt mixes.

\section{Experimental Verification}

\subsection{Test Setups}

5.1.1 Static Creep/Flow Time $\left(F_{T}\right)$ Test

A flow time $\left(\mathrm{F}_{\mathrm{T}}\right)$ test is a triaxial static compressive creep test at which a total straintime relationship for a specimen is measured in the laboratory under unconfined or confined conditions. A $\mathrm{F}_{\mathrm{T}}$ test is used to determine the instantaneous elastic and plastic components, as well as the viscoelastic and viscoplastic components of the material's response as shown in Fig. 1. The relationship could be divided into three major zones: the primary zone (initial stage); the secondary zone (linear portion); and the tertiary flow zone (the portion in which the strain increases significantly) at which failure occurs.

A study by Witczak et al. (2002) suggested that the higher the slope of the linear portion of the graph (secondary zone) the higher the permanent deformation under loading would be. Furthermore, the $F_{T}$ is defined as the postulated time when shear deformation, under constant volume, starts. In this study, the specimens were subjected to a static axial load of $207 \mathrm{kPa}$ and were conducted without confinement at a testing temperature of 54.4 ${ }^{\circ} \mathrm{C}$.

\subsubsection{Flow Number $\left(F_{N}\right)$ Test}

Another approach of measuring permanent deformation of an asphalt mix is the flow number $\left(\mathrm{F}_{\mathrm{N}}\right)$ test. It is a triaxial repeated load test conducted with several thousand repetitions of a cyclic load, while recording the cumulative permanent deformation as a function of the number of load cycles, as shown in Fig. 2, where the relation could be divided into three major zones similar to the $\mathrm{F}_{\mathrm{T}}$ test.

The $F_{N}$ is defined as the number of load repetitions at which shear deformation, under constant volume, starts (Witczak et al. 2002). Specimens were tested using a loading cycle of 1.0 second. The loading cycle consisted of a 0.1 second haversine load of $207 \mathrm{kPa}$ followed by a 0.9 second rest at a testing temperature of 54.4 ${ }^{\circ} \mathrm{C}$.

\subsection{Tested Mixes Properties and Samples Preparation}

Two Superpave mixes with different properties were used and are listed in Table 1. Samples were compacted using a Superpave Gyratory Compactor (SGC) to a height of $175 \mathrm{~mm}$ with $9 \%$ air voids. These samples were then cored and sawed to obtain a sample measuring $100 \mathrm{~mm}$ in diameter and $150 \mathrm{~mm}$ in height. These samples had a $7 \%$ air void, as per the sample preparation procedure for the $F_{T}$ and Number Tests (Witczak et al. 2002).

\subsection{PFC ${ }^{2 D}$ Simulations and Results}

To conduct simulations using $\mathrm{PFC}^{2 \mathrm{D}}$ software, tested specimens were modeled. The model developed initially for this study was constructed of a wide range of particle (sphere) sizes, thus approximating the irregular matrix of the cross-section of an asphalt mix sample (Fig. 3). During this initial phase, the goal was to create a model that simulated actual physical samples. Unfortunately, the analysis of such a model did not converge and no solution was obtained. Then it was decided to 
Utilizing a Simple Numerical Model in Discrete Element Analysis to Simulate Flow Time and Number Tests of .....

model asphalt mix samples as a homogeneous set of 5,000 particles arranged in rows where a solution was obtained (Fig. 4). One of the major benefits of using a homogeneous particle configuration is the significant decrease of time needed to analyze the model by excluding packing procedure. Then contact bond properties were identified and modeled using the sea ice model Eqn. (1). To utilize the sea ice model, the model parameters should be

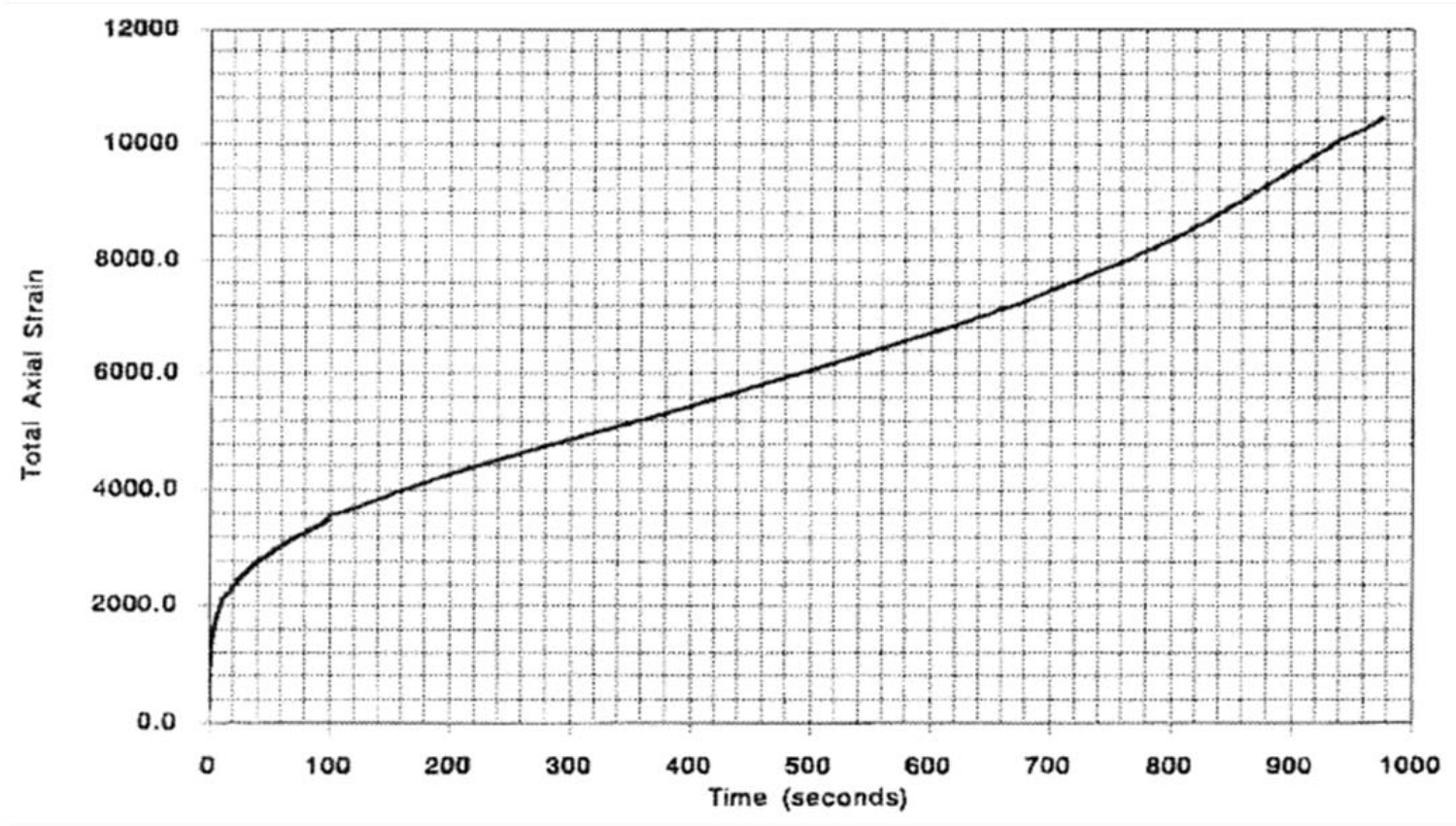

Figure 1. Typical Flow Time Test Results for Asphalt Mixes (After Witczak et al. 2002).

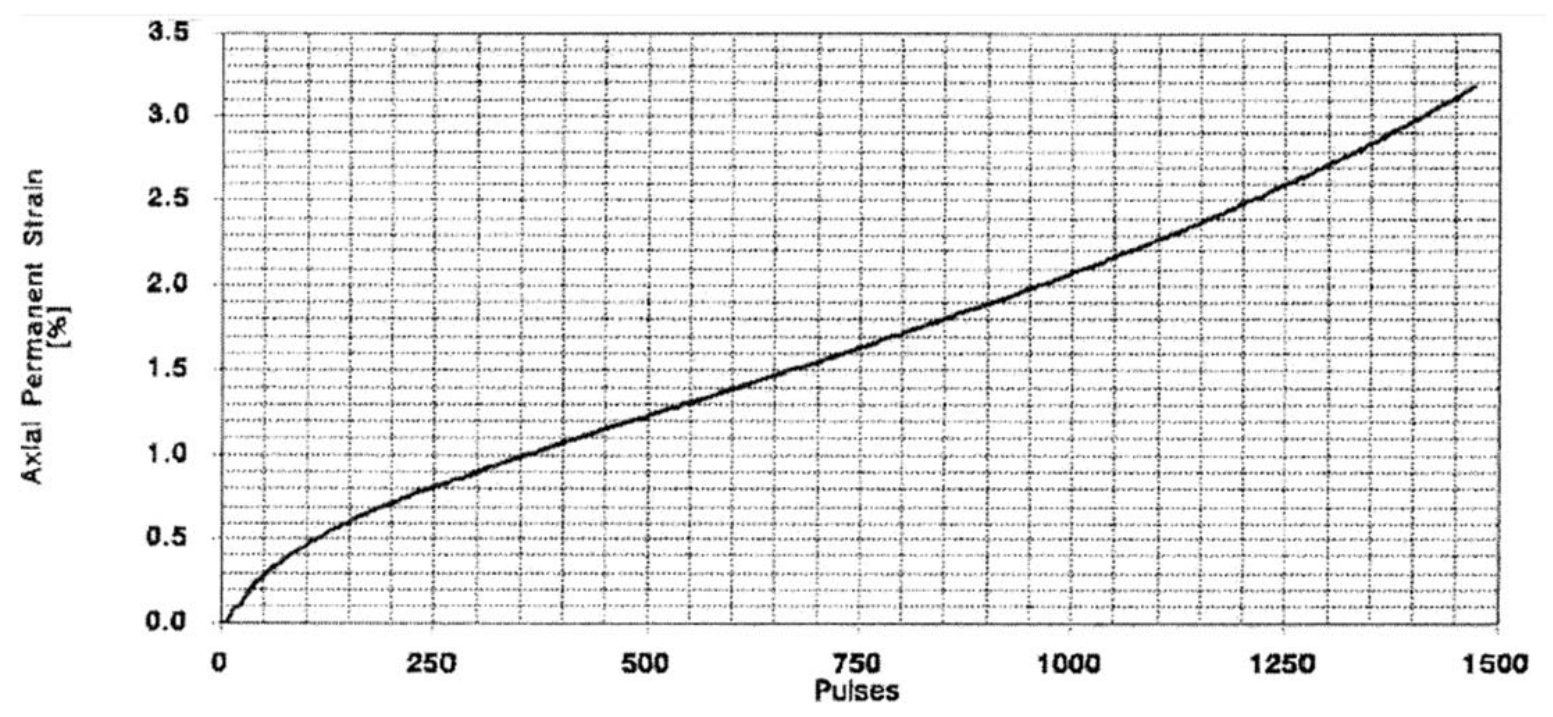

Figure 2. Typical Flow Number Test Results for Asphalt Mixes (After Witczak et al. 2002).

determined. These parameters were obtained from a previous study (Abu Abdo 2012) (Table 2).

Actual results of the $F_{T}$ and $F_{N}$ tests were used to determine the model parameters.
Mixes 1 and 2 had the same model parameters except for the $e_{v o}$. It was suggested that the $e_{v o}$ 
parameter was related to the asphalt binder grade (viscous part of the mix) and since the tested mixes had different binders (Table 1) it was expected that the $e_{v o}$ would be different for both mixes.
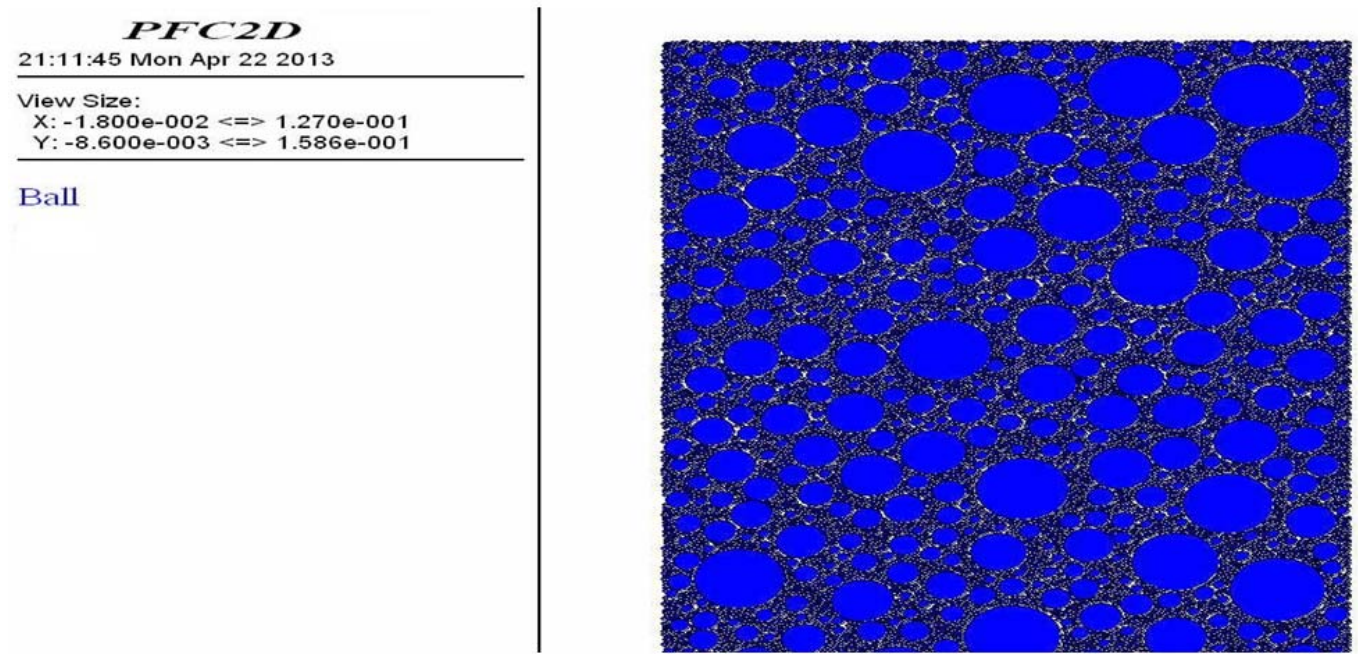

Figure 3. Original Element Assembly (Flow Time Test Model).

PFC2D

Step 1 20:03:41 Mon Apr 222013

View Size:

$X:-2.703 e-002<=>1.270 e-001$

$\mathrm{Y}:-8.075 \mathrm{e}-003<=>1.696 \mathrm{e}-001$

Ball

Wall

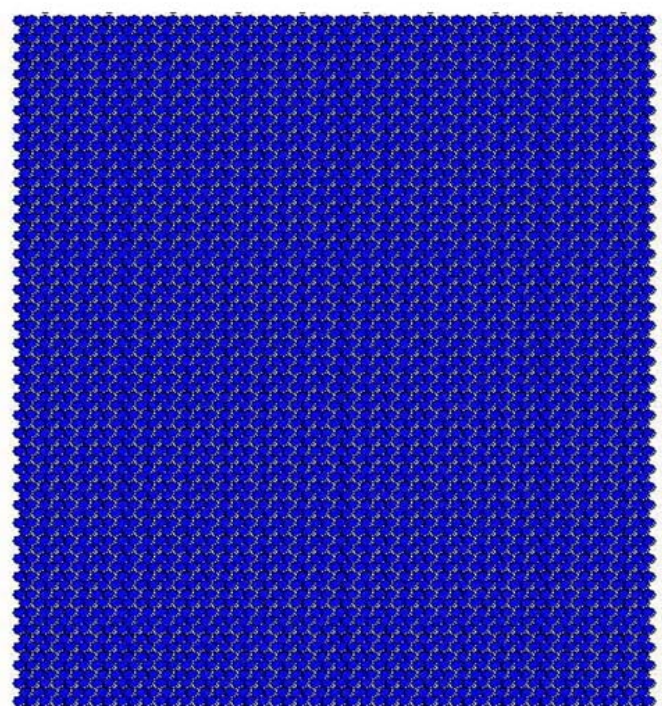

Figure 4. Final Element Assembly (Flow Time and Number Test Models).

Similar to $\mathrm{F}_{\mathrm{T}}$ and $\mathrm{F}_{\mathrm{N}}$ test setups, a simulated specimen using $\mathrm{PFC}^{2 \mathrm{D}}$ software was loaded by assigning forces (constant for the $\mathrm{F}_{\mathrm{T}}$ test and cyclic for the $\mathrm{F}_{\mathrm{N}}$ test) to the bottom particles to 
Utilizing a Simple Numerical Model in Discrete Element Analysis to Simulate Flow Time and Number Tests of .....

simulate the lower loading plate in both tests setups (Fig. 5). The displacements of top particles were prohibited to simulate fixed top plate that acts as a support.

Laboratory test results for the $\mathrm{F}_{\mathrm{T}}$ test (Fig. 6) showed that Mix 1 failed (tertiary flow zone) at a lower number of cycles $\left(t_{f}=1025 \mathrm{sec}\right)$, while
Mix 2 did not fail. Thus, it could be concluded that Mix 2 would perform better than Mix 1 under the same loading conditions. This could be explained by the better mix properties of Mix 2 (ie. larger aggregates sizes and higher binder grade).

Table 1. Mix properties as detailed by Abu Abdo (2012).

\begin{tabular}{lcc}
\hline \multicolumn{1}{c}{ Parameter } & Mix 1 & Mix 2 \\
\hline Job Mix Design Class & $19.0 \mathrm{~mm}$ & $25.4 \mathrm{~mm}$ \\
Binder Grade & PG 58-34 & PG 70-28 \\
Asphalt Content & $4.6 \%$ & $5.0 \%$ \\
Gmm & 2.801 & 2.458 \\
\%Passing Sieve Size & & \\
$25 \mathrm{~mm}$ & $100 \%$ & $98 \%$ \\
$19 \mathrm{~mm}$ & $96 \%$ & $96 \%$ \\
$12.5 \mathrm{~mm}$ & $79 \%$ & $82 \%$ \\
$9.5 \mathrm{~mm}$ & $70 \%$ & $73 \%$ \\
$4.75 \mathrm{~mm}$ & $46 \%$ & $55 \%$ \\
$2.36 \mathrm{~mm}$ & $28 \%$ & $36 \%$ \\
$1.18 \mathrm{~mm}$ & $18 \%$ & $24 \%$ \\
$0.6 \mathrm{~mm}$ & $12 \%$ & $13 \%$ \\
$0.3 \mathrm{~mm}$ & $9 \%$ & $9 \%$ \\
$0.15 \mathrm{~mm}$ & $5 \%$ & $6 \%$ \\
$0.07 \mathrm{~mm}$ & $3.5 \%$ & $4.4 \%$ \\
\hline
\end{tabular}

Table 2. Sea ice model parameters for asphalt mixes as detailed by Abu Abdo (2012).

\begin{tabular}{lll}
\hline Parameter & Mix 1 & Mix 2 \\
\hline$s$ & 1.229378 & 1.229378 \\
$a_{T}$ & $3.14 \times 10^{-04} \mathrm{~s}^{-1}$ & $3.14 \times 10^{-04} \mathrm{~s}^{-1}$ \\
$c$ (Static loading) & 7.5 & 7.5 \\
$c$ (Dynamic loading) & 2.0 & 2.0 \\
$b$ & 0.34 & 0.34 \\
$n$ & 3 & 3 \\
$e_{v o}$ & $6.59 \times 10^{-06} \mathrm{~s}^{-1}$ & $1.78 \times 10^{-07} \mathrm{~s}^{-1}$ \\
\hline
\end{tabular}

Then laboratory test results were compared to the simulated tests. As shown in Fig. 6, $\mathrm{PFC}^{2 \mathrm{D}}$ simulation slightly over-predicted the total strain of Mix 1 until the $\mathrm{F}_{\mathrm{T}}$ was reached, where the tested samples started to flow and shear deformation began (tertiary flow zone). On the other hand, PFC2D simulation approximately matched the measured values of Mix 2. 


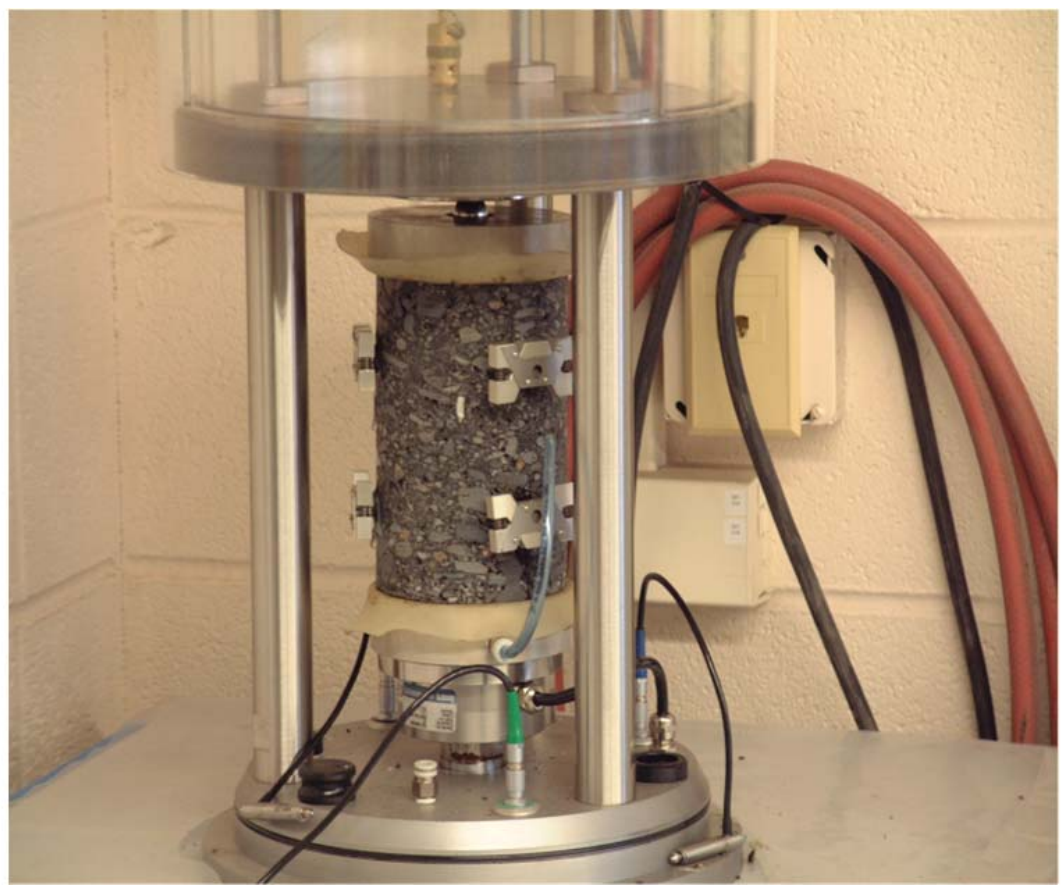

Figure 5. Flow Time (FT) and Number (FN) Test Setups.

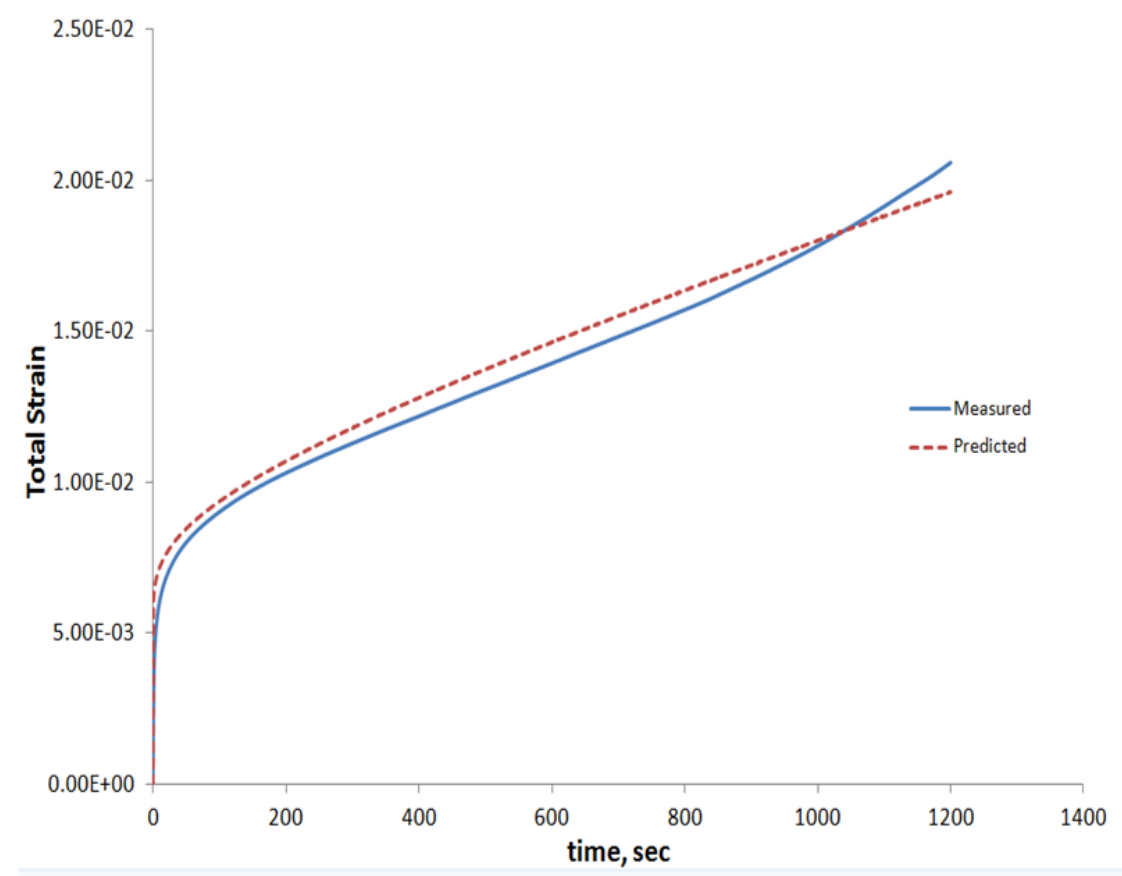

Figure 6-a. Measured vs. Fitted Model Results of Total Strain Determined in Flow Time Test (Mix 1). 
Utilizing a Simple Numerical Model in Discrete Element Analysis to Simulate Flow Time and Number Tests of .....

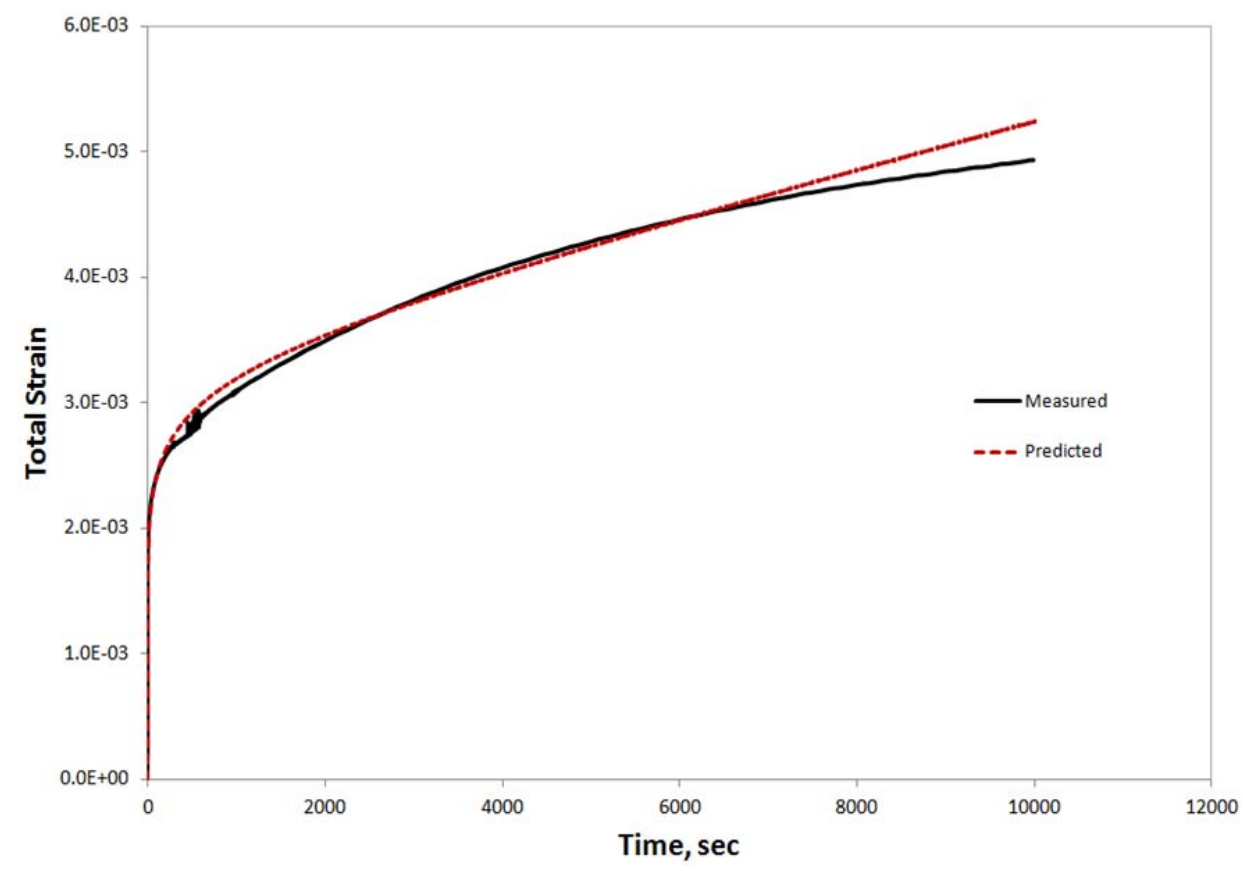

Figure 6-b. Measured vs. Predicted Results of Total Strain Determined in Flow Number Test (Mix 2).

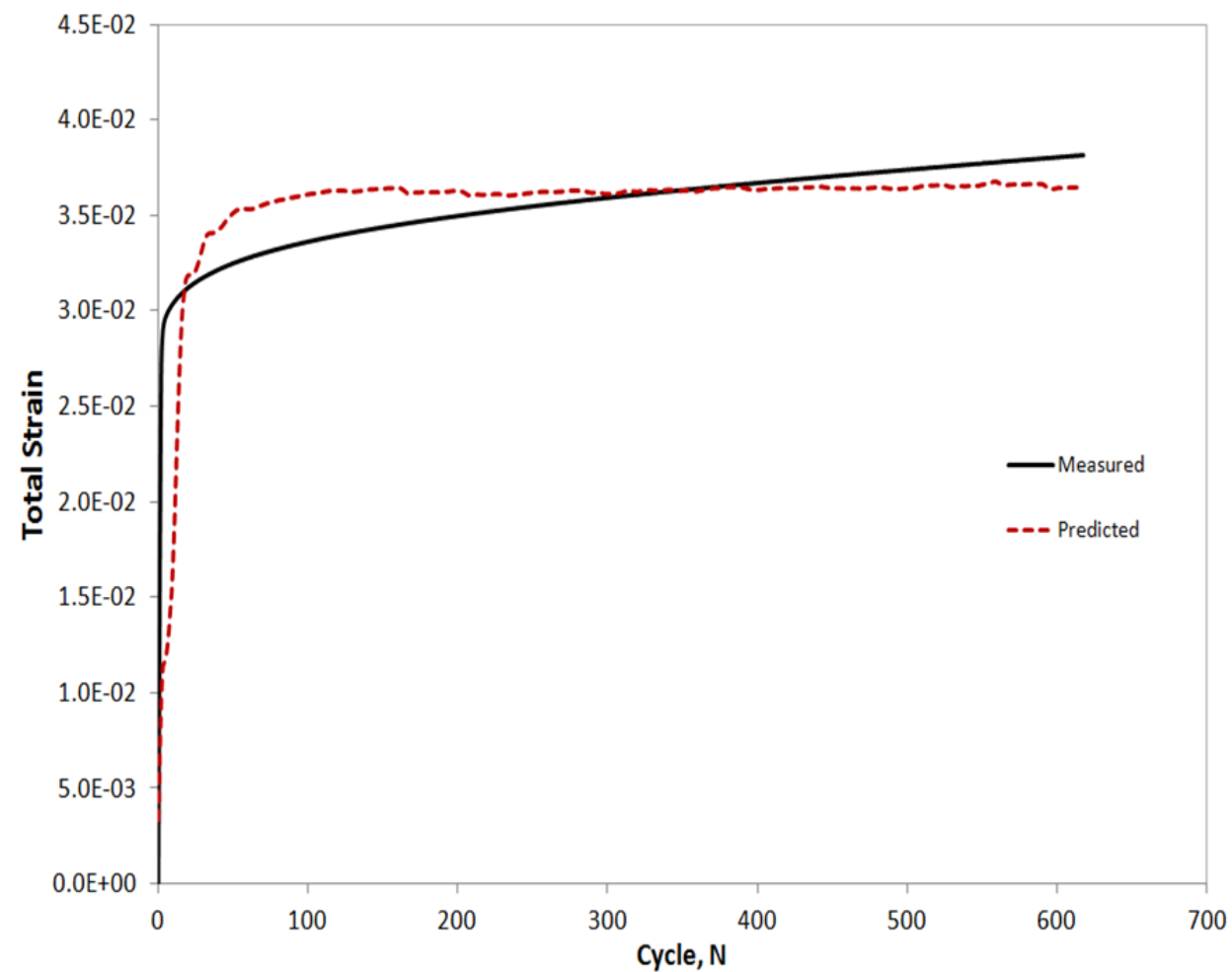

Figure 7. Measured vs . Predicted Results of Total Strain Determined in Flow Number Test (Mix 2). 
To confirm the effectiveness of the sea ice model under different loading conditions, Mix 2 was tested using the $\mathrm{F}_{\mathrm{N}}$ test (cyclic loading) setup. As shown in Fig. 7, $\mathrm{PFC}^{2 \mathrm{D}}$ simulation results over-predicted total strain at an earlier stage (primary zone) and then under-predicted the total strain at the secondary and tertiary flow zones. Further, it was observed that the total strain predicted by $\mathrm{PFC}^{2 \mathrm{D}}$ reached an upper limit. The model parameters might need fine tuning to achieve better results. In addition, it was speculated that if PFC2D model was constructed of a wide range sizes of randomly distributed particles (Fig. 3), simulation results would be more accurate since it represents an actual cross-section of a tested asphalt mix sample.

\section{Conclusions}

Nowadays different and harsher loading conditions exist for asphalt pavements. Therefore, the current design methods, which are based on simple models and assume that asphalt mixes have an elastic and isotropic nature, are not efficient. These methods cannot accurately predict failure as before. A more realistic and applicable approach is needed to account for the visco-plastic behavior and anisotropic nature of asphalt mixes. To prevent failures and undesired effects due to permanent deformations, many numerical models were developed to predict permanent deformation in asphalt mixes. Unfortunately, these models include many specific parameters, which makes their use impractical. This study described the use of a simple viscoelasto-plastic model that has been used successfully in determining Sea Ice distresses under different wind loads. The model was used in the DEM, embedded in the PFC $2 \mathrm{D}$ software. $\mathrm{PFC}^{2 \mathrm{D}}$ was used to simulate the $\mathrm{F}_{\mathrm{T}}$ and $F_{N}$ tests. Two Super pave mixes were used; results of the $\mathrm{F}_{\mathrm{T}}$ test showed that Mix 2 would perform better than Mix 1 under the same loading conditions. Furthermore, a PFC $2 \mathrm{D}$ simulation of the $\mathrm{F}_{\mathrm{T}}$ test results slightly overpredicted the total strain of Mix 1 and approximately matched the measured values of Mix 2.

To validate the utilization of the adopted model under different loading conditions, a simulation of Flow Number test was conducted using Mix 2. Results by $\mathrm{PFC}^{2 \mathrm{D}}$ simulations over-predicted the total strain at the early stage then under-predicted the total strain at the final stages. In addition, it was observed that total strain reached an upper limit, it is suggested that the model parameters might need fine adjusting to achieve better results.

Overall, results from this study indicated that the sea ice model could be utilized effectively in the DEM via PFC ${ }^{2 D}$ software. Additionally, flexible pavement simulation in $\mathrm{PFC}^{2 \mathrm{D}}$ could be adapted to predict deformation on a larger scale and under different loading conditions.

\section{References}

Abbas A, Masad E, Papagiannakis T, Harman $\mathrm{T}$ (2007), Micromechanical modeling of the viscoelastic behavior of asphalt mixtures using the discrete-element method. International Journal of Geomechanics 7:131-139.

Abu Abdo A, Eckwright F, Jung SJ, Bayomy F, Nielsen R (2012), Evaluation of SCNB testing procedure for hot mixture asphalt. Proceedings of the Institution of Civil Engineers: Transport 167:48-58.

Abu Abdo A (2012), Simplified numerical modeling for asphalt mixes. International Journal of Pavement Research and Technology (IJPRT). 5:40-45.

Abraham CL, Maas SA, Weiss JA, Ellis BJ, Peters CL, Anderson AE (2013), A new discrete element analysis method for predicting hip joint contact stresses. Journal of Biomechanics 46:1121-1127.

Buttlar WG, Paulino GH, Song SH (2003), Application of graded finite elements for asphalt pavement analysis. Computational Fluid and Solid Mechanics, Proceedings of Second MIT Conference on Computational Fluid and Solid Mechanics 157-161.

Cai W, McDowell GR, Airey GD (2013), Discrete element modelling of uniaxial constant strain rate tests on asphalt mixtures. Granular Matter 15:163-174.

Collop AC, McDowell GR, Lee YW (2006), Modelling dilation in an idealized asphalt mixture using discrete element modelling. Granular Matter 8:175-184. 
Cundall PA, Strack ODL (1979), Discrete numerical model for granular assemblies. Géotechnique 29(1):47-65.

Goda TJ, Ebert F (2005), Three-dimensional discrete element simulations in hoppers and silos. Powder Technology 158:58-68.

Itasca Consulting Group Inc. (2006), Particle flow code in 2 dimensions user's guide. Minneapolis, Minnesota: Itasca Consulting Group Inc.

Jiang MJ, Xiao Y, Chen SL, Hu HJ, Wu XF (2010), Discrete element analysis of bearing mechanism of single pile in sand under vertical load. Yantu Lixue/Rock and Soil Mechanics 31:366-372.

Krabbenhoft K, Lyamin AV, Huang J, Vicente da Silva M (2012), Granular contact dynamics using mathematical programming methods. Computers and Geotechnics 43:165-176.

Lau M, Lawrence KP, Rothenburg L (2011), Discrete element analysis of ice loads on ships and structures. Ships and Offshore Structures 6:211-221.

Liu Y, You Z, Zhao Y (2012), Threedimensional discrete element modeling of asphalt concrete: size effects of elements. Construction and Building Materials 37:775782.

Mahmoud E, Masad E, Nazarian S (2010), Discrete element analysis of the influences of aggregate properties and internal structure on fracture in asphalt mixtures. Journal of Materials in Civil Engineering 22:10-20.

Masad E, Tashman L, Little D, Zbib H (2005), Viscoplastic modeling of asphalt mixes with the effects of anisotropy, damage and aggregate characteristics. Mechanics of Materials 37:1242-1256.

Mas ID (2006), Water inflow into excavations in fractured rock-A three-dimensional hydro-mechanical numerical study. International Journal of Rock Mechanics and Mining Sciences 43:705-725.

Mellor M (1981), Fracture toughness measurement for ice. CRREL Technical Memorandum, Hanover, New Hampshire, USA, U.S. Army Corps of Engineers, Cold
Regions Research and Engineering Laboratory. Nakamura H, Fujii H, Watano S (2013), Scaleup of high shear mixer-granulator based on discrete element analysis. Powder Technology 236:149-156.

Schwarz J, Weeks WF (1977), Engineering properties of sea ice. Journal of Glaciology 19: 499-531.

Shibata N, Tomita N, Ikeuchi K (2003), Numerical simulations on fatigue destruction of ultra-high molecular weight polyethylene using discrete element analyses. Journal of Biomedical Materials Research - Part A, 64(3):570-582.

Tashman L, Masad E, Little D, Zbib H (2005), A microstructure-based viscoplastic model for asphalt concrete. International Journal of Plasticity 21:1659-1685.

Yang J, Zhang X, Zhu HR (2012), Discrete element simulation on tri-axial shear test of asphalt mixtures. Journal of Building Materials 15:64-68.

Ye Y, Yang X, Chen C (2009), Experimental researches on visco-elastoplastic constitutive model of asphalt mastic. Construction and Building Materials 23:3161-3165.

Witczak MW, Kaloush K, Pellinen T, AlBasyouny M, Von Quintus H (2002), Simple performance test for superpave mix design. NCHRP Report 465, TRB, Washington DC, USA.

You Z (2003), Development of a micromechanical modeling approach to predict asphalt mixture stiffness using the discrete element method. PhD Dissertation, University of Illinois at Urbana-Champaign.

You Z, Buttlar WG (2006), Micromechanical modeling approach to predict compressive dynamic moduli of asphalt mixtures using the distinct element method. Transportation Research Record 1970:73-83.

Zelelew HM, Papagiannakis AT (2009), DEM simulation of asphalt concrete uniaxial creep. Sixth International Conference on Maintenance and Rehabilitation of Pavements and Technological Control (MAIREPAV6), Turin, Italy. 